\title{
Hedonomia e Design Emocional: A importância da aparência (requisito estético; funções simbólica e estética) na seleção de um produto pelos usuários
}

Hedonomics and emotional design: the importance of appearance (aesthetic requirement, symbolic and aesthetic functions) in the selection of a product by users

MARIÑO, Suzi; D.Sc.; Universidade Federal da Bahia e Universidade do Estado da Bahia

suzimarino@gmail.com

SILVEIRA, Carina; M.Sc.; Universidade do Estado da Bahia e Universidade Federal da Bahia

carinassilveira@gmail.com

SILVA, Paulo; Universidade do Estado da Bahia

henriqueoupaulo@gmail.com

SANTOS, Ruth; Universidade do Estado da Bahia

ruth.designmoda@gmail.com

\section{Resumo}

Esta pesquisa teve por objetivo mostrar o estudo comparativo das bicicletas mountain bike e de transporte, tendo como base o experimento realizado por MariñoPequini (2005) onde foi avaliado os níveis de dor/desconforto considerando a postura do tronco e o ajuste do selim e assim encontrar a relação do usuário com o produto, a fim de definir parâmetros de usabilidade entre ambos. Esses estudos resultaram na elaboração de pesquisa para através da opinião dos usuários investigar a importância da aparência (requisito estético/simbólico) durante a seleção dos produtos. A partir disso, objetiva-se avaliar de acordo com os requisitos estéticos; função estética e nível visceral o comportamento dos usuários na escolha de um produto, enfatizando a importância desses aspectos no design de produtos.

Palavras Chave: ergonomia; hedonomia; bicicletas e usuários.

\begin{abstract}
This research aimed to show the comparative study of mountain bike and Transport bicycles, based on the experiment carried out by MariñoPequini (2005), where the pain / discomfort levels were evaluated considering the trunk posture and the saddle adjustment and thus to find the relationship between the user and the product, in order to define usability parameters between the two. These studies will resulted in the elaboration of research for through the opinion of users investigating the importance of appearance (aesthetic / symbolic requirement) during product selection. From this, we aim to evaluate according to the aesthetic requirements; aesthetic function and visceral level the behavior of the users in the choice of a product, emphasizing the importance of these aspects in the design of products.
\end{abstract}

Keywords: ergonomics; hedonomics; bicycles and users. 


\section{Introdução}

Esta pesquisa se propôs estimular o desenvolvimento de projeto de produtos que atendam aos requisitos técnico, ergonômico e estético e as funções prática, estética e simbólica, a partir do experimento realizado por MariñoPequini (2005) onde a autora utilizou a metodologia ergonômica para encontrar a relação do usuário com o produto e assim, definir parâmetros de usabilidade entre ambos. Ressaltando então a importância de atender também ao requisito estético e as funções estéticas e simbólicas de forma a torná-los mais atraentes atingindo a emoção no nível visceral dos usuários.

Os atuais estudos voltados para o design mostram como é feita a escolha de um objeto pelo usuário. Surgem estudos que mostram que não só os critérios técnico e funcional, mas, na maioria das vezes, as escolhas são feitas com base nas memórias (DAMAZIO, 2013) e a emoção (NORMAN, 2008; DESMET, 2009; TONETTO, 2011) que o objeto traz. No design, a aparência dos objetos está relacionada a seus atributos de configuração física e de identidade visual gerada através da cognição humana interligada às emoções. O valor atribuído a um objeto, seja ele de utensílios ou tecnológicos, está diretamente relacionado à experiência afetiva do usuário. Ou seja, a emoção implica nas escolhas que fazemos e não a qualidade de usabilidade que os produtos oferecem às pessoas.

\footnotetext{
As emoções causadas pelas interações com um produto podem ser influenciadas por fatores como estética, funcionalidade, marca, entre outros, além de serem complexas, pessoais, mutáveis, temporais e culturalmente dependentes. Podemos atender as emoções como reações afetivas que, pela sua intensidade, nos mobilizam para algum tipo de ação. Elas são poderosas manifestações dos nossos instintos e impulsos, resultantes de alterações fisiológicas controladas pelo sistema cerebral, que responde ao conteúdo dos pensamentos relativos a um estímulo recebido. (FONTOURA e ZACAR, 2008, p.30).
}

Desta forma, o trabalho a ser desenvolvido se insere no contexto de pesquisa que tem como propósito validar a hipótese de que os usuários escolhem seus produtos mais pela aparência em detrimento dos requisitos ergonômico e tecnológico, fazendo um estudo comparativo da aparência das bicicletas mountain bike e de transporte com base na pesquisa desenvolvida por MariñoPequini (2005).

A aparência do objeto, além de reunir o requisito estético e as funções estética e simbólica, atinge o nível visceral, caracterizado por ser um dos três níveis estruturais do cérebro. $O$ nível visceral é o primeiro estágio cognitivo da relação do usuário com o objeto. Através dele julgamos o que é certo ou o que é errado, bom ou ruim, mesmo antes de ter um contato físico com o produto. A emoção se encontra em paralelo com a estética, atratividade e beleza, também está diretamente ligada a aparência, ou seja, ao nível visceral (NORMAN, 2008). Tal fato tem despertado um grande interesse em diversas áreas de conhecimento como a neurociência, psicologia, filosofia, antropologia e sociologia, entre outras.

\footnotetext{
Uma das maneiras pelas quais as emoções trabalham é por meio de substâncias químicas neuroativas que penetram determinados centros cerebrais e modificam a percepção, o comportamento e os parâmetros de pensamento. (NORMAN, 2008).
}

Ao projetar com foco na emoção, os designers estarão voltando sua atenção ao usuário e ao modo como interagem e interpretam o meio físico e social. A usabilidade e tecnologia são importantes, mas sem diversão, alegria, entusiasmo, raiva, frustração e prazer nossas vidas seriam incompletas. Sendo assim, pretendeu-se com o desenvolvimento desta pesquisa propor resultados 
através da opinião dos usuários que serão utilizados para elaborar recomendações projetuais no requisito estético/simbólico de um produto a fim de torná-los mais atraentes e competitivos.

\section{Ergonomia aplicada ao design de bicicletas}

As bicicletas de transporte e mountain bike selecionadas para o estudo comparativo desta pesquisa tiveram como referência o experimento realizado por MariñoPequini (2005), onde a autora avaliou os níveis de dor/desconforto considerando a postura do tronco e o ajuste do selim.

A autora utilizou a metodologia ergonômica para encontrar a relação do usuário com o produto e assim, definir parâmetros de usabilidade entre ambos. Foi utilizada como aparato do experimento a bicicleta ergométrica Monark Ergomedic 828-E (Figuras 1 e 2). A bicicleta foi ajustada de acordo com o biótipo dos usuários, nos tipos tradicional e aerodinâmico (Figuras 3 e 4) as quais, nesta pesquisa correspondem respectivamente a bicicleta de transporte e mountain bike.
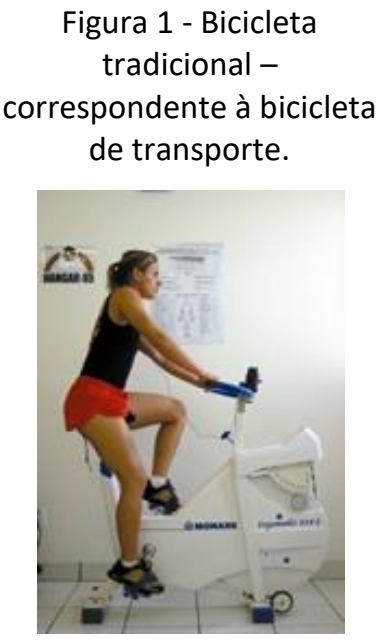

Fonte:

MariñoPequini (2005)
Figura 2 - Bicicleta aerodinâmica correspondente a bicicleta mountain bike.

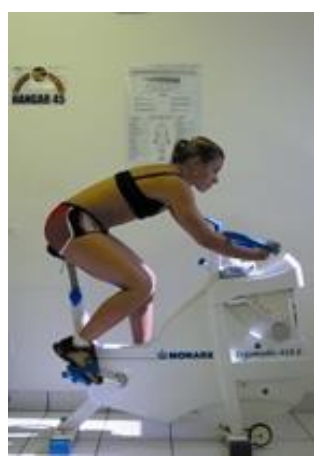

Fonte:

MariñoPequini (2005)
Figura 3 - Postura assumida em bicicleta tradicional - transporte

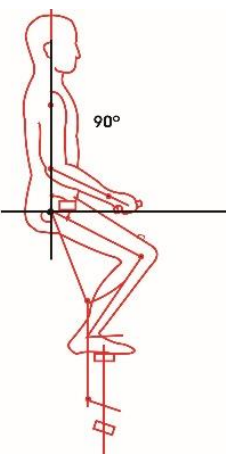

Fonte: Dreyfuss (1996 apud MARIÑOPEQUINI, 2005)
Figura 4 - Postura assumida em bicicleta aerodinâmica - mountain bike

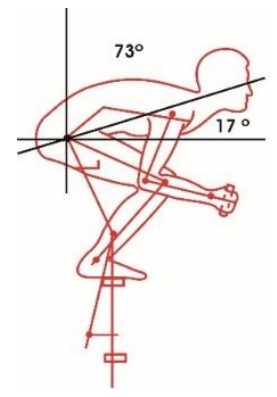

Fonte: Dreyfuss (1996 apud MARIÑOPEQUINI, 2005)

Para a inclusão da amostra a autora estabeleceu os seguintes critérios: Indivíduos saudáveis; Faixa etária: definida de acordo com o nível de condicionamento físico dos participantes a partir do desempenho da frequência cardíaca; Sexo: masculino e feminino; Prática de atividade física; Estatura: do 2,5ㅇ percentil feminino ao 97,5으 percentil masculino, conforme recomendações antropométricas de Diffrient et al. (1981); e Habitantes da cidade do Salvador.

Foram consideradas três tipos de variáveis: Variáveis Independentes: Tipo da bicicleta (Tradicional - transporte e Aerodinâmica -mountain bike); Altura do selim (correto; $10 \%$ abaixo do correto; e 10\% acima do correto; conforme apresentaremos a seguir); Variável Dependente: Nível de desconforto/dor (Escala de CORLLET e WILSON, 1986:326 apud MARIÑOPEQUINI, 2005); e Variáveis controladas: Sexo; Estatura; Alimentação; Postura na bicicleta; Ajustes da bicicleta; Carga da bicicleta; Sequências das sessões; Frequência cardíaca; Intervalo entre as sessões de 30 minutos; Práticas de outras atividades físicas no período do experimento.

Os resultados do experimento mostraram a variação na postura do tronco em duas situações 
diferentes para que fossem avaliados os níveis de desconforto em 28 regiões do corpo. Para isso, foram medidos os tempos pedalados, a velocidade, a distância percorrida e os batimentos cardíacos, e, ao final de cada sessão, foi solicitado aos participantes que respondessem a escala de avaliação corporal para detectar os níveis de desconforto/dor nas várias regiões do corpo e, de posse destes resultados, indicar qual o tipo de bicicleta mais confortável do ponto de vista postural, se a postura tradicional - transporte - com o tronco ereto, ou se a postura aerodinâmica - mountain bike - com o tronco flexionado; e, do ponto de vista dimensional no que diz respeito à altura do selim.

A amostra da população selecionada partindo de alguns critérios citados anteriormente foi de homens com faixa etária média de 30 anos, peso médio $77 \mathrm{~kg}$ e estatura média de $179,7 \mathrm{~cm}$, e mulheres com faixa etária média de 33 anos, peso médio $57 \mathrm{~kg}$ e estatura média de 162,7cm.

\subsection{Bicicleta Tradicional - transporte}

Pode-se observar que a bicicleta tradicional - transporte, foi bem aceita pela maioria dos participantes (Quadro 1), já que cerca de 90\% destes não sentiram nenhum desconforto em $95 \%$ das partes do corpo.

\subsection{Bicicleta aerodinâmica - mountain bike}

Na bicicleta aerodinâmica (Quadro 2), notou-se que os dados se apresentam heterogêneos, o que conclui a divergência de opinião em relação ao nível de desconforto entre homens e mulheres.

Enfim, a autora concluiu a partir dos resultados que a bicicleta tradicional - transporte é mais confortável, já que cerca de $90 \%$ dos avaliados não sentiram nenhum desconforto/dor em $95 \%$ das partes do corpo, enquanto que a bicicleta aerodinâmica - mountain bike foi bastante desconfortável, pois o nível de desconforto/dor apresentou-se mais intenso na região púbica, isto é, 85\% deles consideraram "moderado", "bastante" e "intolerável"; destes, 60\% sentiram intolerável desconforto. Além disso, uma boa parte dos ciclistas sentiu alguns incômodos nos membros inferiores do corpo, como é o caso dos pés, em que $60 \%$ e $45 \%$ sentiram "algum", "bastante" e até mesmo "intolerável" desconforto/dor no pé direito e no pé esquerdo, respectivamente.

Com bases nesses resultados as bicicletas foram selecionadas, para avaliarmos também qual a percepção dos usuários em relação a essas bicicletas no que diz respeito à conforto avaliado só pela aparência destas, resultados estes apresentados ao final deste artigo.

\section{Design Emocional e os três níveis de processamento cerebral}

Os estudos de Norman (2008) sobre design emocional sugerem que os atributos humanos de cognição resultam em três diferentes níveis de estrutura do cérebro: a camada automática, préprogramada, chamada de nível visceral. A parte cujo os processos cerebrais controlam o comportamento cotidiano, conhecida como nível comportamental. E a parte contemplativa do cérebro ou nível reflexivo.

Na prática, segundo o autor, o nível visceral é de rotinas fixas e anterior ao pensamento. Diz respeito ao impacto inicial de um produto, sua aparência, toque e sensação. Nele se formam as primeiras impressões. O nível comportamental é comum em operações rotineiras, e também não é um nível consciente. Diz respeito ao uso, e sobre a experiência com o produto. No nível reflexivo a consciência e os mais altos níveis de sentimentos, emoções e cognição residem. 
Para constatar a importância da aparência na seleção de produtos pelos usuários, elaboramos uma pesquisa que deverá ser respondida por usuários, que vivem diretamente e diariamente em um posto de trabalho e constituem importantes fundamentos para o projeto ergonômico.

\section{Hedonomia}

Os autores Hancock, Pepe e Murphy, foram os responsáveis pela autoria do primeiro artigo que relacionou a Ergonomia com o prazer no uso de produtos. Através da proposta de Helander e Tham (2004), a teoria recebeu o nome de hedonomia, do grego hedonomos, hedo significa prazer, e nomos significa leis, princípios.

A hedonomia é a relação com a Ergonomia ocupando-se dos fatores de usabilidade com a experiência prazerosa e individualização. Vários designers perceberam que foi tornando-se cada vez mais necessário trazer essa experiência prazerosa aos usuários (MONT`ALVÃO e DAMAZIO, 2008).

O objetivo da hedonomia é esclarecer a existência de uma afetividade e satisfação das pessoas com os seus produtos. Um exemplo claro dessa relação afetiva, é ouvir alguém dizer que ama algum produto, pois ele oferece tudo o que precisa.

A sensação de prazer que sentimos ao consumir está ligada com a percepção de satisfação e, consequentemente, felicidade que conseguimos transmitir ao compartilharmos nosso objeto de consumo com os outros, seja de forma direta ou indireta.

No artigo "sobre amar um produto: os princípios fundamentais" Beatriz Russo e Paul Hekkert argumentam que pessoas amam produtos que contêm significados simbólicos. Através desses significados ocorre a experiência emocional, onde emoções e sentimentos são evocados. Saber como e porque o amor é vivenciado pelas pessoas nesta interação, através dos princípios sobre emoção e amor é vital para o designer. Afinal, esse profissional é responsável por compreender e explorar os sentidos humanos para transformar elementos tangíveis e criar possibilidades de proporcionar prazer através das interações entre pessoas e objetos de consumo.

\section{Limites dos campos da Ergonomia, Hedonomia e Design Emocional}

A Ergonomia é o estudo das relações entre homem e máquina, visando segurança, funcionalidade e usabilidade. "É uma forma de se agregar valor aos produtos, ajudando a torna-los fáceis de usar". (JORDAN, 2000). Hancock et al. (2005) destacam que a gênese do termo hedonomia é idêntica à da Ergonomia. Porém, se a ênfase da Ergonomia está na prevenção de constrangimentos e segurança dos usuários na interação com sistemas cotidianos, a hedonomia concentra-se em promover o prazer com esses mesmos sistemas Hancock (2005). Apesar disso, a Ergonomia e a hedonomia possuem o mesmo objetivo: otimizar a interação humano-tecnologia.

Um diagrama que explica a relação entre a Ergonomia e hedonomia, conhecido como Concepção de Maslow (Figura 5), foi proposto por Hancock et al. (2005). Ele estabelece que enquanto a Ergonomia se ocupa com questões de segurança, funcionalidade e usabilidade, a hedonomia além da usabilidade tem como foco, a promoção do prazer através das experiências prazerosas e a individualização. 
Figura 5.- Hierarquia da ergonomia e da hedonomia a partir da concepção de Maslow

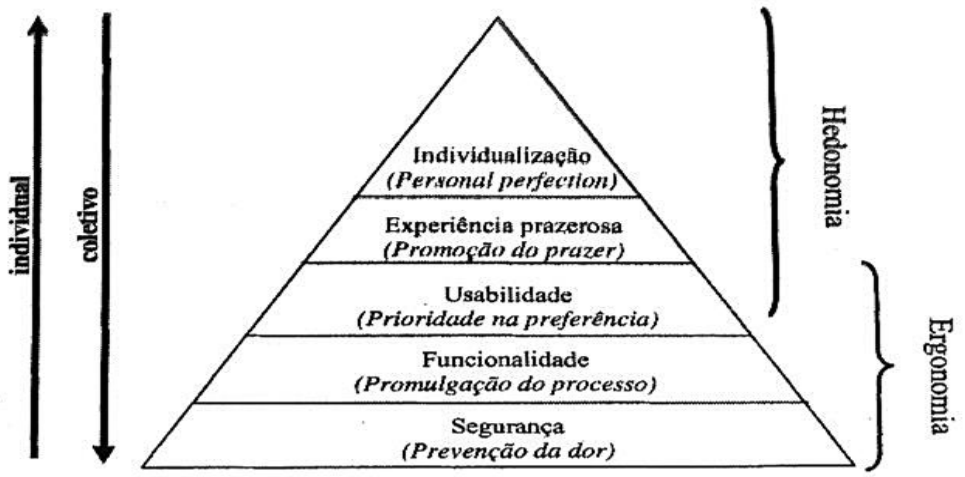

Fonte: Handock et al., (2005 apud MONT'ALVÃO e DAMÁZIO., 2008)

De acordo com o diagrama da figura 5, a segurança e a funcionalidade são necessidades básicas do indivíduo. Através da interação com o produto, a usabilidade poderá levar a uma experiência prazerosa. A individualização é a auto realização do usuário. É o nível mais alto, que só pode ser atendido se todas as outras necessidades básicas já tiverem sido satisfeitas.

O design emocional é muito ligado a Ergonomia devido a interação entre o homem e o objeto/máquina. Só que o tipo de interação que se discute no Design Emocional é "afeto" do homem com o produto. Alguém poderia dizer: "eu amo o meu celular", por exemplo. Literalmente pessoas amam consumir determinados produtos e a marca passa a fazer parte da vida do indivíduo às vezes passando de pai para filho. Se refletirmos, talvez até usamos os mesmos produtos que foram dos nossos avôs, pais e, por mais que o outro produto " $Y$ " seja a mesma coisa e não mude nada em termos de qualidade, preço, pode existir clientes que não fazem questão de experimentar outra coisa porque preferem o que já conhecem. (MONT`ALVÃO; DAMAZIO, 2008).

\section{Proposta metodológica da pesquisa: Uma avaliação sobre o comportamento dos usuários na escolha de um produto}

Para aplicação da pesquisa foram analisados e definidos por Mariño e Silveira (2016) os parâmetros necessários à seleção de bicicletas, pelos usuários.

MariñoPequini (2005) a partir das notas de Palmer (1983), levantou que o produto deve atender determinados requisitos para atingir os objetivos esperados. A partir de Lobach (2001), MariñoPequini (2005) destaca que os aspectos essenciais de relações dos indivíduos com os objetos são as suas funções, que possibilitam a satisfação de necessidades.

A pesquisa possibilitou comparar e avaliar através da análise de questionários a relação dos usuários com as bicicletas de transporte e mountain bike, a partir dos resultados do experimento de MARIÑOPEQUINI (2005), bem como aspectos de avaliação emocional: segurança, velocidade, resistência e conforto que foram definidos por Mariño e Silveira (2016:6) (Quadro 1) como proposta metodológica de pesquisa.

Com base nos estudos conclusivos apresentados nos Quadros 1 e 2 foi elaborada a matriz de avaliação emocional das bicicletas (Quadro 3) na qual foram referidos às duas bicicletas os parâmetros de emoções pessoais, variando-se entre seguro, não-seguro, veloz, não-veloz, elegante, não-elegante, resistente, não-resistente, belo, não-belo, confortável e não-confortável, assim como, entrevista semiestruturada caracterizada por ter questionamentos básicos apoiados em 
teorias que se relacionam ao tema da pesquisa (TRIVIÑOS; 1987, p.146). Cabe salientar que a matriz gerada também levou em consideração o estudo da metodologia Kansei (LEE; MARGHAN; HEEMAN, 2017) que tem por prática a compreensão das emoções pessoas para projetação de novos produtos.

Quadro 1 - Quadro comparativo dos parâmetros de avaliação emocional da bicicleta de transporte e mountain bike

\begin{tabular}{lll} 
Parâmetros de avaliação emocional & Bicicleta de transporte & Mountain bike \\
\hline Segura & Sim & Sim \\
\hline Veloz & Não & Sim \\
\hline Resistente & Sim & Sim \\
\hline Confortável (postura e ajuste do selim) & Sim & Não \\
\hline
\end{tabular}

Fonte: Mariño e Silveira (2016)

Quadro 2 - Avaliação dos aspectos atendidos pelas bicicletas de transporte e mountain bike

\begin{tabular}{lll} 
Níveis & Bicicleta de transporte & Mountain bike \\
\hline Comportamental (usabilidade - postura e ajuste do selim) & Atende & Não atende \\
\hline Visceral (aparência) & Não Atende & Atende \\
\hline Reflexivo & Pode Atender & Pode Atender \\
\hline Funções & Bicicleta de transporte & Mountain bike \\
\hline Ergonômica (postura e ajuste do selim) & Atende & Não atende \\
\hline Prática (função) & Atende & Atende \\
\hline Simbólica (aparência) & Não Atende & Atende \\
\hline Requisitos & Bicicleta de transporte & Mountain bike \\
\hline Ergonômico (postura e ajuste do selim) & Atende & Não Atende \\
\hline Tecnológico (resistência e materiais industriais) & Atende & Atende
\end{tabular}

Fonte: Mariño e Silveira (2016) 
Quadro 3 - Matriz de avaliação emocional das bicicletas

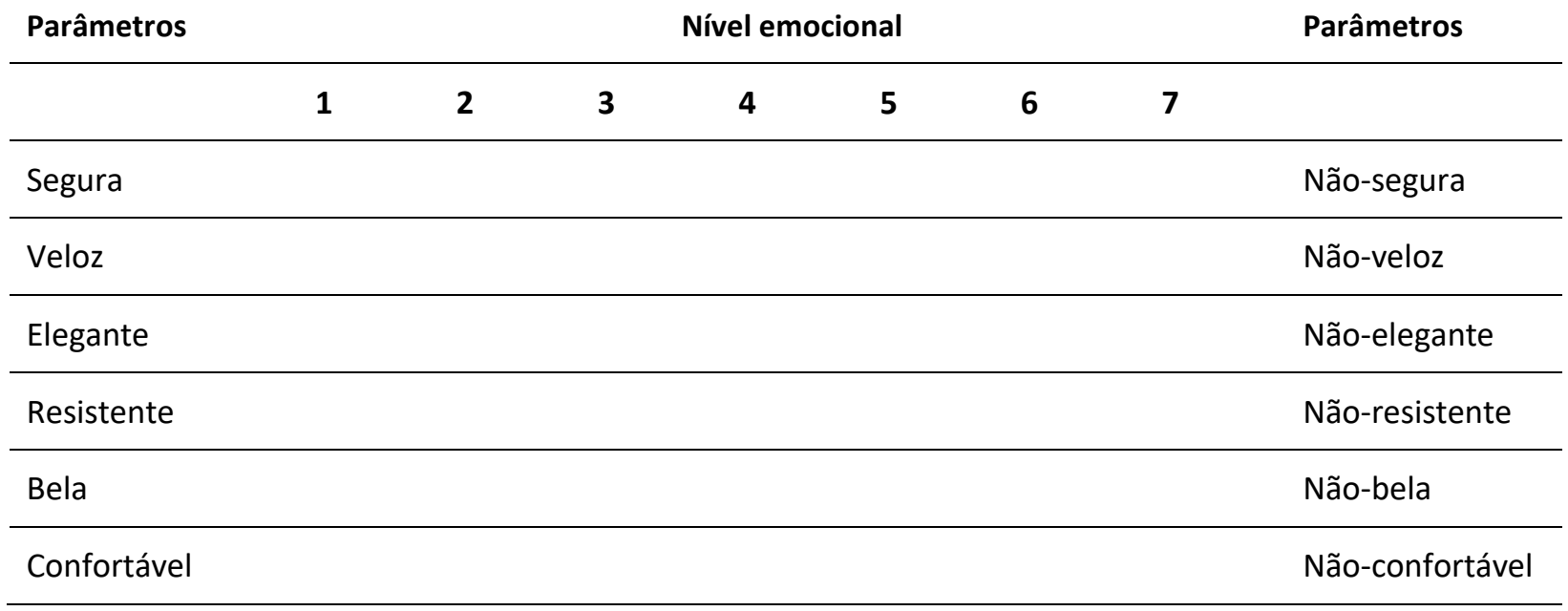

Fonte: Mariño e Silveira (2016)

Para a coleta final de dados da pesquisa tornou-se necessário a compreensão das partes das bicicletas analisadas (Figuras 6 e 7) bem como a relação das mesmas com os parâmetros de avaliação emocional, para tanto foi desenvolvida a matriz apresentada no Quadro 4, que foi aplicada aos usuários.

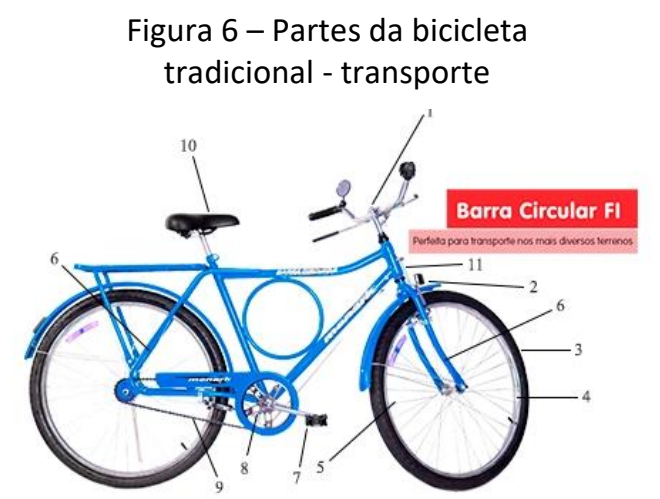

Fonte: http//:monark.com.br/produtos
Figura 7 - Partes da Bicicleta aerodinâmica mountain bike

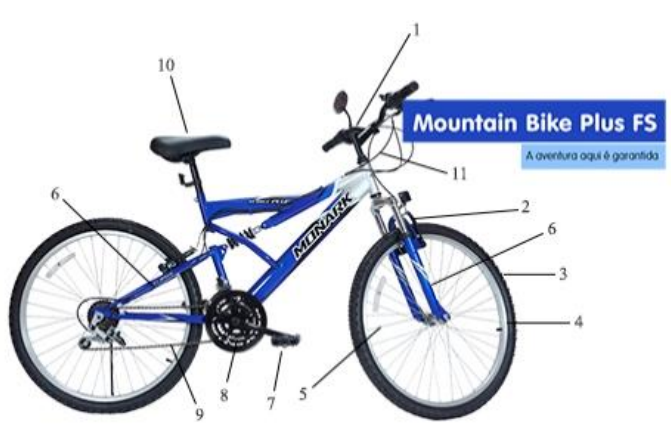

Fonte: http//:monark.com.br/produtos

Como pressuposto das etapas da coleta de dados, a pesquisa foi dividida em duas etapas

10 - definição da amostra de usuários para aplicação das matrizes, que em consideração 2 grupos: grupo por idade e por prática/uso de bicicletas. No grupo por idade existia 2 subgrupos com usuários nas faixas etárias de 20 a 35 anos e de 36 em diante; e no grupo por prática/uso terão 2 subgrupos, 1 de usuários praticantes de atividades físicas com uso de bicicleta e outro de usuários não praticantes. Tal divisão da amostra pretendeu avaliar a influência da idade e da prática de atividade física nos parâmetros;

2ㅇ - foram apresentadas as bicicletas aos usuários baseado na análise visual das mesmas os usuários preencheram a matriz de avaliação emocional (Quadro 3) e, em seguida, a matriz de correlação dos parâmetros com as partes das bicicletas (Quadro 4). 
Quadro 4 - Matriz de correlação dos parâmetros com as partes das bicicletas

\begin{tabular}{|l|l|l|l|l|l|l|}
\hline & \multicolumn{5}{|c|}{ Parâmetros } \\
\hline $\begin{array}{l}\text { Partes da } \\
\text { bicicleta }\end{array}$ & Segura & Veloz & Elegantc & Resistente & Bela & Confortável \\
\hline Guidåo & & & & & & \\
\hline Freio & & & & & & \\
\hline Aro & & & & & & \\
\hline Raios & & & & & & \\
\hline Garfos & & & & & & \\
\hline Pedal & & & & & & \\
\hline Coroas & & & & & & \\
\hline Correntc & & & & & & \\
\hline Selim & & & & & & \\
\hline $\begin{array}{l}\text { Cabos dos } \\
\text { freios }\end{array}$ & & & & & & \\
\hline Quadro & & & & & & \\
\hline Pncus & & & & & & \\
\hline
\end{tabular}

Fonte: Mariño e Silveira (2016)
Legenda: parte das bicicletas

1. Guidão

2. Freio

3. Aro

4. Pneus

5. Raios

6. Garfos

7. Pedal

8. Coroa

9. Corrente

10. Selim

11. Cabo de freio

12. Pneus

$\mathrm{Na}$ primeira sessão foram levantadas duas questões. A primeira questão se referiu a avaliação de seis parâmetros de acordo com a aparência da bicicleta de transporte. E na segunda questão, o entrevistado avaliou os mesmos parâmetros referentes à aparência da mountain bike.

Nesta sessão o entrevistado deveria escolher apenas uma opção para cada quesito. Para a construção desta sessão foi levado em consideração a metodologia Kansei, constituída na aplicação de níveis de 1 a 7 em ordem decrescente, onde o parâmetro positivo foi atribuído ao nível 7 e o negativo ao nível 1. Entretanto, a plataforma não permitiu distribuir os níveis em ordem decrescente de acordo com o método escolhido, o que levou à alteração da ordem dos parâmetros. Ressalta-se que nesta sessão foi fundamental anexar imagens em cada questão para que o público visualizasse a aparência das bicicletas acompanhando cada quesito.

$\mathrm{Na}$ segunda sessão o entrevistado informou sua opinião relacionada aos parâmetros emocionais, de acordo com as partes que compõem as bicicletas, sendo dividida em dois quadros direcionados para cada uma. As partes escolhidas foram: guidão, freio, aro, raios, garfos, pedal, coroas, corrente, selim, cabos dos freios, quadro e pneus, identificadas através de legenda acompanhando a imagem (Figura 8). A sessão foi feita com base na matriz de correlação dos parâmetros com as partes das bicicletas definidas por Mariño e Silveira (2016).

A pesquisa possibilitou comparar e avaliar através da análise dos questionários a relação dos usuários com as bicicletas de transporte e mountain bike, bem como aspectos de avaliação emocional: segurança, velocidade, resistência e conforto definidos por Mariño e Silveira (2016:6).

Figura 8 - Matriz de opinião relacionada aos parâmetros emocionais.

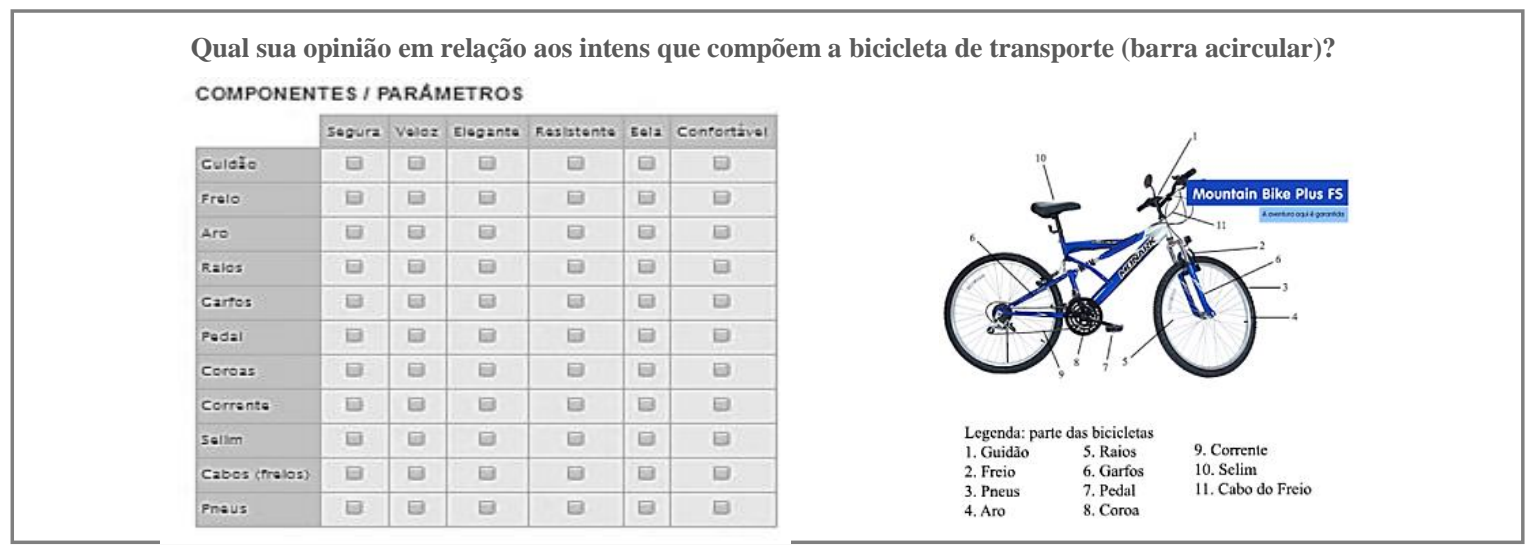

Fonte: Mariño e Silveira (2016) 
Ressalta-se que o usuário poderia selecionar mais de uma opção de parâmetro para cada parte que compõe a bicicleta, escolhida de acordo com o que usuário considerasse relevante.

A propagação da pesquisa deveria ocorrer de maneira rápida e acessível, portanto, foi escolhida a plataforma on-line JotForm, software responsável pela criação de formulários, assim como a criptografia dos dados fornecidos pelos usuários, acesso mobile e a integração com e-mails e redes sociais, favorecendo o compartilhamento e mobilidade da entrevista.

De acordo com a análise realizada pela plataforma, em 20 dias de formulário ativo, foram feitas 241 visualizações, 102 respostas, com média de 6 minutos por pessoa. 33 usuários tiveram contato com a pesquisa através de hardwares e 208 através de dispositivos móveis. Destaca-se que o limite permitido pela plataforma através da conta gratuita era de 100 respostas, as quais o JotForm desconsiderou as duas últimas, o que não influenciou no resultado final da pesquisa. Dentre o público cinco pessoas eram de outros países. (Figura 9)

Figura 9 - Respostas por localização de usuários.

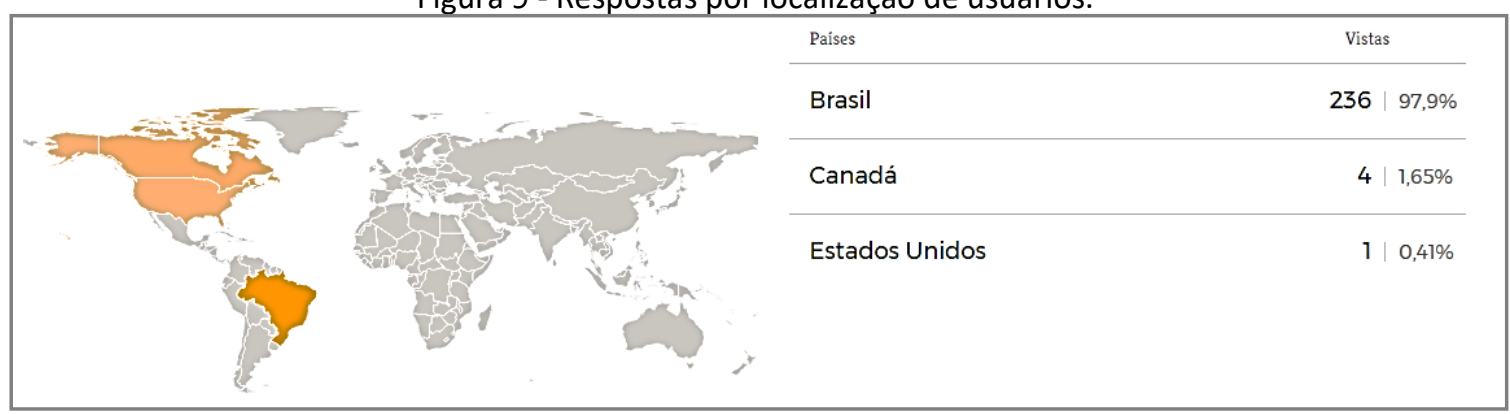

Fonte: https://www.jotform.com/analytics/71278635384667

Do total de 100 respostas, $52 \%$ foram de usuários do sexo feminino e $48 \%$ de usuários do sexo masculino. No entanto, esse fator não foi tratado como critério relevante ou que determinasse no resultado final de forma direta, visto que, o objetivo da pesquisa foi verificar a influência emocional na escolha de produtos, o que não é determinado necessariamente pelo fator sexo.

Com base nos resultados quantitativos da pesquisa obtidos pela plataforma JotForm, as respostas foram organizadas e analisadas através de gráficos facilitando a compreensão dos resultados. Na primeira etapa considerou-se os resultados dos parâmetros avaliados pelos usuários de cada bicicleta separadamente. Na segunda etapa, foram comparados os resultados dos parâmetros emocionais entre as bicicletas de transporte e mountain bike. 


\subsection{Resultados quantitativos da Bicicleta de transporte de acordo com a escala Kansei, sessão 1, questão 1: Pode-se observar que a bicicleta tradicional - transporte}

De acordo com os níveis da escala Kansei onde 1 é um nível emocional negativo, 4 intermediário e 7 positivo, foi feita a soma da quantidade de usuários que responderam de acordo com a relevância de cada parâmetro: Seguro, não-seguro, veloz, não-veloz, elegante, não-elegante, resistente, não-resistente, bela, não-bela, confortável e nãoconfortável. (Quadro 5)

No final foram destacados os níveis que mais pontuaram em cada parâmetro. 0 nível da escala Kansei que mais pontuou na bicicleta de transporte foi o nível 4, sendo os parâmetros velocidade, elegância e conforto.

Quadro 5 - Matriz de avaliação emocional da bicicleta de transporte

\begin{tabular}{|c|c|c|c|c|c|c|c|c|}
\hline \multirow[t]{2}{*}{ Parâmetros } & \multicolumn{6}{|c|}{ Nível emocional } & \multicolumn{2}{|r|}{ Parâmetros } \\
\hline & 1 & 2 & 3 & 4 & 5 & 6 & 7 & \\
\hline Segura & $x$ & & & & & & & Não-segura \\
\hline Veloz & & & & $x$ & & & & Não-veloz \\
\hline Elegante & & & & $x$ & & & & Não-elegante \\
\hline Resistente & $x$ & & & & & & & Não-resistente \\
\hline Bela & & & & & & & $x$ & Não-bela \\
\hline Confortável & & & & $x$ & & & & Não-confortável \\
\hline
\end{tabular}

Fonte: Adaptado de Silveira e Mariño (2016).

\subsection{Resultados quantitativos da mountain bike de acordo com a escala Kansei, sessão 1, questão 2:}

Na mountain bike também foram destacados os níveis que mais pontuaram em cada parâmetro. O nível da escala Kansei que mais pontuou foi o nível 7, sendo os parâmetros segurança, velocidade, elegância resistência e beleza. (Quadro 6) 
Quadro 6 - Matriz de avaliação emocional da mountain bike

\begin{tabular}{llllllll} 
Parâmetros & \multicolumn{9}{c}{ Nível emocional } & Parâmetros \\
\hline Segura & $\mathbf{1}$ & $\mathbf{2}$ & $\mathbf{3}$ & $\mathbf{4}$ & $\mathbf{5}$ & $\mathbf{6}$ & $\mathbf{7}$ \\
\hline Veloz & $\mathrm{X}$ & & & & & & Não-segura \\
\hline Elegante & $\mathrm{X}$ & & & & & & Não-veloz \\
\hline Resistente & $\mathrm{X}$ & & & & & & Não-elegante \\
\hline Bela & $\mathrm{X}$ & & & & & & Não-resistente \\
\hline Confortável & & $\mathrm{X}$ & & & & & Não-bela \\
\hline
\end{tabular}

Fonte: Adaptado de Silveira e Mariño (2016).

Comparando estes resultados nos quais os usuários avaliaram as bicicletas apenas pelas suas aparências através da visualização de fotos, não tendo a experiência do uso destas, diferente do experimento realizado por MariñoPequini (2005) no qual os usuários usaram das bicicletas, verificamos que a aparência do produto é fator determinante na escolha deste. No experimento citado, os usuários escolheram a bicicleta de transporte como a mais confortável e a mountain bike como a mais desconfortável depois de 30 minutos pedalando estas bicicletas. No entanto, só pela aparência, a bicicleta mountain bike foi avaliada no nível 7 em $86 \%$ dos itens, apenas o item conforto que foi avaliada no nível 6 que também é considerado um nível muito positivo já que a escala tem uma amplitude de 1 a 7. Já a bicicleta de transporte, apesar de ter sido avaliada como a mais confortável pelos que a pedalaram no experimento MariñoPequini (2005), ao ser avaliada pela aparência (foto), os únicos itens que foram avaliados no nível 7, foram segurança e resistência, o item conforto ficou com o nível 4, 57\% menor que a da bicicleta mountain bike e o item beleza foi avaliado como nível 1, ou seja, extremamente negativo, para o que podemos concluir que, a aparência pode influenciar de forma significativa na escolha de um produto, mesmo que este não atenda ao requisito ergonômico ou técnico.

\section{Considerações finais}

Durante o estudo foi importante fazer uma reflexão histórica sobre o design emocional e a hedonomia, a fim de entender como se dão os processos neurais e como as emoções são essências no controle cognitivo.

A partir do que foi exposto vimos que as emoções provêm de um estado afetivo intenso e são fundamentais para a sobrevivência e desenvolvimento saudável dos seres humanos. Por esse motivo, os indivíduos atribuem significados aos produtos, e estes 
diariamente participam de nossas ações, interferem nas relações, e evocam emoções e sentimentos que afetam diretamente as nossas condutas. Em outras palavras, as formas visuais (requisito estético) influenciam nas reações das pessoas em função dos objetos de consumo.

O design emocional e suas ramificações são de extrema importância, afinal devem ser pensados e utilizados desde a concepção de um projeto, com o propósito de promover experiências prazerosas e sentimentos positivos que possibilitem uma identificação dos usuários de forma direta a ponto de sentirem seus desejos, gostos, preferências e valores representados.

Através da pesquisa foi possível investigar que a aparência dos objetos é um requisito importante e deve ser levada em consideração ao projetar produtos, pois além de atingir o nível visceral do cérebro, influencia na seleção dos produtos pelos usuários.

Salienta-se o desafio da pesquisa em termos de aplicação de conceitos ainda pouco explorados, contudo fez-se necessário tal desbravamento para se galgar novos patamares ao design. Esta pesquisa abre possibilidades para se pensar e observar a utilização das referências emocionais, no design de produtos.

\section{Referências}

DAMÁZIO, Vera. Design, memória, emoção: uma investigação para o projeto de produtos memoráveis. Barbacena: Eduemg, 2013. 19 p.

DESMET, P. 2009. Special Issue Editorial: Design \& Emotion. International Journal of Design, 3(2):1-6.

COSTA, Filipe Campelo Xavier e TONETTO, Leandto Miletto. Design Emocional: conceitos, abordagens e perspectivas de pesquisa. Strategic Design Research Journal, 4(3): 132-140. Setembro-dezembro, 2011.

FONTOURA, Antônio M. e Cláudia R. Hasegawa, ZACAR. Quando o design mexe com a gente. In: abc Design. Ed n. 25. Curitiba, 2008. ISSN 1676-5656.

LEE, Erika Yamamoto; MARGHAN, Viviane i Gaspar Ribas El e HEEMAN, Adriano. Fundamentos da engenharia kansei: Uma revisão bibliográfica e sua relação entre o design de superfície e o interior de aeronave. Revista Ergodesign \& $\mathbf{H C l}$, [S.I.], v. 4, n. Especial, p. 33-39, jan. 2017. ISSN 2317-8876.

LÖBACH, Bernd. Design Industrial: bases para a configuração dos produtos industriais. São Paulo: Edgar Blücher, 2001

MARGHANI, V. G. R.; GABARDOA, A. C.; SILVA, A. S. de A.; SILVA, F. C. da; SALATA, N. S. Kansei Engineering: metodologia orientada ao consumidor para suporte a decisão de projeto. In: 8o Congresso Brasileiro de Gestão de Desenvolvimento de Produtos. 2011. Porta Alegre. Setembro, 2011. 
MARINO, Suzi; SILVEIRA, Carina. Escalas de avaliação de percepção de parâmetros em relação a produtos: Requisitos, Funções e Níveis cerebrais. Salvador: UFBA: PPGAV, 2016. 5 p. Disponível em: <www.posdesign.com.br>. Acesso em: 01 fev. 2017.

MARIÑOPEQUINI, Suzi. A evolução tecnológica da bicicleta e suas implicações ergonômicas para a máquina humana: problemas na coluna vertebral $\mathrm{x}$ bicicletas dos tipos Speed e Mountain bike. 2000. 200 f. Dissertação (Mestrado) - Curso de Arquitetura e Urbanismo, Arquitetura, Universidade de São Paulo, São Paulo, 2000.

MARIÑOPEQUINI, Suzi. Ergonomia aplicada ao design de produtos: Um estudo de caso sobre o design de bicicletas. 2005. $630 \mathrm{f}$. Tese (Doutorado) - Curso de Arquitetura e Urbanismo, Arquitetura, Universidade de São Paulo, São Paulo, 2005.

MONT'ALVÃO, Claudia; DAMAZIO, Vera. (Org.) Design, ergonomia e emoção. Rio de Janeiro: Mauad X, 2008. p. 19-30.

NORMAN, Donald A. Design Emocional: Por que adoramos (ou detestamos) os objetos do dia-a-dia. Rio de Janeiro: Rocco, 2008. 278 p. Tradução de: Ana Deiró.

SILVEIRA, Carina Santos; MARIÑO, Suzi Maria. O prazer do vestir - Moda, ergonomia e referências culturais. In: CONGRESSO BRASILEIRO DE ERGONOMIA, 18. 2016, Salvador. 18-congresso-ergonomia-27272. Belo Horizonte, 2016.

TONETTO, Leandro Miletto; COSTA, Filipe Campelo Xavier da. Design Emocional: conceitos, abordagens e perspectivas de pesquisa. Strategic Design Research Journal, Chicago, v. 3, n. 4, p.1-9, set. 2011. Disponível em: <file:///C:/Users/titto/Downloads/4492-14861-1-SM (1).pdf>. Acesso em: 15 out. 2016.

Triviños, A. N. S. Introdução à pesquisa em ciências sociais: A pesquisa qualitativa em educação. São Paulo, Atlas, 1987.

VIANA, Ilca Oliveira. Metodologia de Trabalho Científico: Um enfoque didático da produção científica. São Paulo: Epu, 2001. 304 p. 